\title{
BIOLOGY IN THE TROPICS
}

$\mathrm{A}^{\mathrm{T}}$ $T$ the Cardiff meeting of the British Association for the Advancement of Science on September 1, Dr. G. S. Carter, of the Department of Zoology, University of Cambridge, set the stage in his presidential address on "Tropical Climates and Biology" to Section D (Zoology) for a session on the importance of the tropies to zoology. In the session Dr. Carter's address was followed by a paper on evolution within the tropical belt by Prof. J. E. Wobb, of University College, Ibadan, Nigeria, and by another on tropical fish communities by Dr. Rosemary McConnell (née Lowe), lately of East Africa and now fisheries research officer in British Guiana.

Dr. Carter began by relating that when he was young he was told by his elders that a zoologist's education was not complete until he had visited the tropics and worked on a tropical fauna with its richness and variety of animal life. He believed that this is still true to-day although not, perhaps, for quite the same reasons that led our predecessors to think so. The richness and variety still remain largely unexplored, but we have come to realize that results of work in the tropics are frequently of great general interest to the biologist and may not be such as might be expected from knowledge of the biology of temperate climates.

Both Dr. Carter and Prof. Webb stressed the importance of climate in determining the fauna and flora of a region, and showed that the most unchang. ing of all land climates is to be found in the forests of the humid tropics. Temperato climates, although more moderate in regard to average temperature, in fact have greater seasonal and diurnal variation in this respect than the humid tropics, and thus present a more stringent environment for animal and plant life. In the tropies rainfall is more important than temperature in determining differences between environments, for the regions of high rainfall are covered by forest that gives way to grassland or savanna of increasing dryness in areas of low precipitation and this in turn to desert. Prof. Webb showed that the boundaries of the vegetational zones in Nigeria are related not so much to the amount of the rainfall but to the relative length of the dry period in each year. More accurately it may be said, as Dr. Carter pointed out, that the nature of the environment is controlled by the proportion $(l / g)$ of the gain of water to the environment to its loss, not only in evaporation and run-off but also in transpiration from the vegetation and percolation into the soil. In the rain forests the value of $l / g$ is of the order of 0.2 , so that much of the water flows off the land and the environment is humid. In desorts, $l / g$ may be as high as 200 and in savanna it is probably often near unity. This ratio $l / g$ also controls the diurnal and annual ranges of temperature which are low in humid environments and high in the desert.

Dr. Carter mentioned several examples of work on tropical biology that has given results not to be expected from our knowledge of the temperate regions. In tropical swamps-an environment from which vertebrates and probably many other terrestrial animals almost certainly emerged from water on to land-the water is for all practical purposes stagnant. The content of nutrient salts in these swamps is often high, and at first sight it would be expected that the phytoplankton would be plentiful, but, in fact, both animal and plant plankton are sparse. It seems that the failure of the phytoplankton to grow is due partly to the shallow penetration of light into the shaded and highly coloured water, and partly to the low concentration of dissolved oxygen in the water at levels less than 5 per cent saturation. Dr. Carter suggested that the low concentration of oxygen might be a result of the absence of photosynthesis together with a lack of overturn of the layers of the water. Under conditions giving rise to a steep temperature-gradient from the surface downward with the surface 8-10 degrees C. higher than water at 12-18 in. depth, the water becomes permanently stratified, the lower layers receive no oxygen and in parallel come to contain a high concentration of free carbon dioxide, up to 70 c.c. per litre, which cannot escape by diffusion. This is, therefore, a very difficult environment for animals, and all the fauna shows adaptation to life in a deoxygenated habitat and has developed accessory breathing organs and the like. A study of this question of permanent stratification in shallow tropical waters is clearly important for their future economic development.

Equally unexpected results have been given by work on the sulphur content of tropical fresh waters in Africa by Beauchamp (Nature, 171, 769 ; 1953), where its lack appears to be a limiting factor in the growth of the aquatie fauna. It seems that the sulphur is absorbed from the water of the lake by the planktonic fauna and flora and carried down to the mud in their dead bodies so that the water becomes denuded of sulphur. In the mud the organic sulphur compounds are preserved without breakdown even for the several thousand years required for the deposition of $10-15 \mathrm{~m}$. of mud. Plants rooted in the mud are able to absorb sulphur from this store, which is apparently the only means whereby the sulphur can be carried back into the water. Lake mud can thus be used to improve the fertility of tropical soils and fish ponds.

The control of seasonal rhythms of reproduction and migration in tropical animals is not easy to understand when the changes in climate are slight, yet periodicity of these kinds has been demonstrated in a wide range of equatorial animals. It may be that these rhythms are at least in part endogenous, but it seems there must be some environmental stimulus, physical or other, that controls their periodicity even though we cannot always define it. Clearly this is a subject on which further work is needed.

Dr. Carter ended with the problem of how small mammals are able to satisfy their needs for water under desert conditions without drinking and at temperatures as high as $54^{\circ} \mathrm{C}$. This has been studied by B. and K. Schmidt-Neilson ("Biology of Deserts", Inst. of Biology, London, 1954). It is quite impracticable for the body temperature of a small mammal in the desert to be controllod by sweating, and accordingly sweat glands are reduced. In this case the water balance of the animal is achieved by a reduction of all forms of water loss from the body, utilization of motabolic water, the eating of plants absorbing dew deposited during the cold desort nights and 
sheltering in a burrow during the day. It is evident that this is one complex physiological problem of which there are many in regard to tropical animals.

Prof. Webb remarked that for more than a contury the distribution of animals had been viewed mainly from the point of view of the zoogeographical regions, none of which is exclusively tropical, and that the fauna and flora of the tropical belt as compared with the temperate and arctic regions had escaped detailed geographical analysis. The tropical bolt, however, has a physical basis and unlike the zoogeographical regions must have existed for longer than life itself. An estimate based on the distribution of species in a representative sample of groups of land and freshwater animals suggests that at least 70 per cent of the world's land species occur in the tropics and there is evidence that this is also true for land plants and marine organisms. Moreover, for tropical land animals and plants, an analysis of distribution suggests that not less than 50 per cent of these are found in the forest, most of the remainder being savanna forms. Relating these figures to the areas of the Earth's surface involved we find a density of species in the tropical forest at least three times as great as in savanna and six times that of the temperate region. Thus the number of species is high in the tropical forest and falls more or less progressively with increasing biological stringency of the environment through the tropical grasslands to the desert, on one hand, and from the tropies as a whole through the temperate to the polar regions on the other. This applies to species but not necessarily to higher taxonomic categories, such as the genus and the family where the numbers represented in the tropics may be less than elsewhere. Nor does it appear that the high number of tropical species is related to a greater biomass in the tropies, for there is evidence that this is not greatly in excess, if at all, of the biomass of the temperate region. The density of tropical species, therefore, is evidently due to greater speciation in the tropics than elsewhere, and the problem remains why this should be so.

When the distributions of the present-day families of the vertebrate classes between the tropic and temperate regions are comparcd, it is found that the most-recently evolved group, the birds, has a higher proportion of tropical families than the older group, the mammals, and that the proportion of tropical to temperate families falls steadily through the series reptiles, amphibians, fishes and lampreys. Moreover, the ratios of recent tropical to temperate families for these groups when plotted against the respective times of origin of the groups, as given by the age of the earliest known fossils of each, fall into two approximately parallel linear scries. The first and earlier of these is the Anamnia and the second the Amniota, the break between them evidently representing the point when the reptiles achieved emancipation from water, which opened to them and their successors a new terrestrial path out of the tropics into temperate lands.

The evidence that the proportion of temperate to tropical vertcbrate families has increased regularly with the age of the group suggests that each of the vertebrate classes originated in the tropies and that the rate of evolution of families has been virtually constant, first for the Anamnia and then for the Amniota, since the Ordovician for a period of 350 million years. Prof. Webb pointed out that if there is any truth in the speculation that evolution has been procecding at a more or less constant rate for so long, then it becomes necessary to seek some physical change in the Earth which, by regularly affecting the tropical belt for this period of time, might have controlled the rate of vertebrate evolution.

The zone of transition from tropical forest to savanna consists of an interdigitation of areas of forest and grassland with inliers of savanna in the forest and outliers of forest in the savanna. Slow fluctuation in the extent of the forest in response to climatic changes over the centuries or millenia would result in the formation of new isolated areas of forest or savanna and their subsequent re-incorporation into the parent vegetational belt. The temporary isolation of these patches of vegetation could provide conditions favourable for speciation and perhaps account in part for the high density of species in the tropical forest. If in addition there was also a very much slower, constant and prolonged shift of the land masses through the tropical belt then, at its edge, outliers of tropical vegetation would move into the temperate zone, shrinking and finally disappearing. The isolation, together with the slow environmental change, that this would cause could be part of a mechanism leading to the evolution, at a moro or less constant rate, of forms adaptod to temperate conditions in proportion to their numerical representation in the forest.

Prof. Webb directed attention to the work of Prof. S. K. Runcorn in "Advances in Physies" in 1955, which postulated on palæomagnetic evidence a relative shift of the north magnetic pole from a point near the present equator west of America in the Pre-Cambrian through a wide arc crossing Japan and Siberia to its position at the present. As it is probable that the geographic pole has never been far from the magnetic north, this shift would also imply a corresponding shift of the equator. It is clear, therefore, that there may be some physical evidence for a constant and prolonged movement of the land masses through the tropical belt on which depends the sug. gested mechanism for the evolution at a more or less regular rate of temperate vertebrates from originally tropical forms.

Prof. Webb showed maps on which the equators of the different geological periods were drawn based on Runcorn's positions of the north magnetic pole and noted that the locations of the earliest known fossils of the vertebrate classes all lie within the tropical belts of their periods. He also pointed out that, on this evidence, the equator of the Triassic in which the Rhynchocephalia arose passed through the Bay of Plenty in New Zealand, where lives the tuatara lizard, the last survivor of that group. Moreover, the relative change in position of the equator, also on this evidence, has been about an axis between a point in the Pacific off the west coast of North America and the northern tip of Madagascar since the Silurian. These areas, therefore, may have lain continuously within the tropics for the past 330 million years and may have been the only regions on the Earth's surface to have done so. It may be significant that the Pacific location is near where the primitive molluse Neopilina was recently found, while the seas off North Madagascar are the home of the living colacanths. Perhaps these areas are tho nearest we shall find in fact to the fiction of Conan Doyle's "Lost World". (Recent work by Prof. P. M. S. Blackett, Dr. J. A. Clegg and Mr. P. H. S. Stubbs in Proc. Roy. Soc., A, 256, 291 ; 1960, gives 
palæomagnetic evidence for continental drift. A reassessment of the positions of the fossil equators relative to the land masses will need to be made in the light of this new evidence for drift.)

Dr. Rosemary McConnell ended the symposium with a comparison of the fish faunas of tropical Africa and tropical Amorica. She commented on the great complexity of the tropical fish fauna which, combined with a lack of well-defined seasons, led to many of the difficulties experienced by ecologists in the tropies. The majority of the freshwater fish species of South America and Africa belong to relatively few family groups each of which has undergone remarkable adaptive radiation. The chief of these are the catfishes, the characids and the cichlids, which are common to the two continents and comprise about 70 per cent of the fish fauna. The main difference between the faunas of the two continents is the presence in Africa of numerous species of Cyprinidae and Mormyridae, families absent from South America, where their ecological positions are occupied by the Characidae and Gymnotidae.

The Amazon is by far the richest river system in the world with well over 1,000 known species of fish, and no doubt very many more await discovery. The fish communities there are very complex, many species, often closely related, living in one area as is shown by the fact that a large seine may net as many as 100 species of fish in a single haul in certain parts of the Amazon. A similar though less-extreme situation exists in Africa where, for example, Lakes Tanganyika and Nyasa both have about 200 species of fish, most of them endemic. The question, therefore, arises as to the reason for the complexity of these tropical fish communities. Dr. McConnell suggested that a factor contributing to this could have been profound weather changes of the Quarternary. Just as in the temperate zones the ice ages probably reduced the number of fish species there, so in the tropies the corresponding pluvial and interpluvial periods may well have promoted speciation. For example, in Africa, during a pluvial period, a rise in the level of the lakes would have made new niches for the fish which would afterwards become isolated during the interpluvial period when the lake-level fell, thus providing conditions favourable for speciation. This situation of fluctuating levels in the freshwater habitats is very similar to that proposed by Prof. Webb for the forest.

Dr. McConnell remarked on the extensive adaptive radiation achieved by the Cichlidae, Cyprinidae and
Mormyridae in Africa and the Characidae and catfishes in South America, and outlined the astonishing diversity of form and habit found particularly among the catfishes. In such a complex of species the problems of how populations remain distinct and individuals of one species recognize one another for breeding purposes are not fully understood and certainly cannot be answered completely at the moment. The segregation of many of the species, particularly in the Cichlidae, has undoubtedly been maintained by differences in territorial behaviour, restrictions imposed by different food and breeding requirements and so forth. Recognition of each other by individuals within a species may be achieved again by their seeking similar environmental conditions for breeding purposes. In some cases the fish resort to sound signals for recognition and in this respect parallel many of the insects of the tropical forest. The characid of Guiana streams, Prochilodus, on a spawning run up river sounds like an outboard ongine.

Eating and avoiding being eaten form the predominant theme in the tropics, the biotic relationships appearing to assume greater importance in the general ecology when physical conditions are stable, and much remains to be learnt about the balance between predator and prey. In the absence of welldefined breeding seasons, fish spawn at any time of the year so that young fish and fish at all stages of growth may also be found at all times of the year. The community is thus very uniform and some predators have been able to specialize in feeding only on young fish. In spite of this, however, a balance is maintained, for the food webs are too complex to allow certain species to multiply enormously and thus there is here, just as there is in the tropical forest, no species which can truly be considered dominant.

Dr. Carter remarked in closing his presidential address that, as tropical biology is at a much less advanced stage than that of temperate countries, $i t$ is less difficult in the tropics to find promising lines of work. Yet, when posts in tropical laboratories are advertised, it is not by any means always easy to find people to fill them. One reason for this may well be that the many advantages of work in the tropics are not sufficiently realized by the younger generation of biologists or, for that matter, by the older generation that advises them. Perhaps this session will have shown that the tropics offer new fields to conquer and the chance to view old problems in a new light.

J. E. WeBB

\title{
SPECIFICITY AND INHERITANCE OF ANTIBODY RESPONSE : A POSSIBLE STEERING MECHANISM
}

\author{
By DR. B. CINADER \\ Department of Medical Biophysics, University of Toronto, and Division of Biology, \\ Ontario Cancer Institute, Toronto
}

\begin{abstract}
$\mathrm{A}$ NIMALS may be tolerant ${ }^{1}$ to their own circulating antigens and hence to a very large number of antigenic determinants. An antigenic determinant of a heterologous protein could only induce an antibody response if it were different from any of the determinants of the autologous proteins. The specificity of the antibody response would thus depend on
\end{abstract}

the relation between the structure of autologous and heterologous antigen. Furthermore, tho determinant sites of autologous proteins are not always the same in individuals of the same species, and as a consequence the determinants of a heterologous protein which could elicit an antibody response would not be necessarily identical, in composition or number, in 